\title{
DAMPAK ADAPTASI PRESENTASI TREE-VIE $W$ TERHADAP NIAT UNTUK MELAKUKAN PEMBELIAN SECARA ONLINE: EMOSI DAN SIKAP PENGGUNA SEBAGAI MEDIATOR (DIDASARKAN PADA STIMULUS-ORGANISM-RESPONSE MODEL)
}

\author{
Amir Hidayatulloh \\ Universitas Ahmad Dahlan \\ amir_dayat@yahoo.com
}

\begin{abstract}
The purpose of this reserach is to find out whether a method of adaption presentation tree-view has an impact on individual intention to purchase in online store which mediated by emotion and attitude toward the website. Sample was collected by using purposive sampling method with criterias, such as a person who is ever browsing in online store and at least has two times online purchasing history. Data was collected by using survey both distributed to responden directly as well as through internet, and 220 sample done by testing. Statistical test was done using WarpPLS 3.0. The result is user emotion increases when website use tree-view, whereas attitude toward the website don't increase when website use tree-view. User emotion at browsing activity in website use tree-view adaptation and positive attitude of user on the website, finally encourage individual to have purchase intention.
\end{abstract}

Keywords: tree-view based adaptation presentation, intention on online buying.

\begin{tabular}{l}
\hline PENDAHULUAN \\
Perkembangan internet yang begitu \\
cepat akan membawa dampak pada perubahan \\
perilaku manusia. Perubahan perilaku tersebut \\
antara lainperubahan perilaku dalam melakukan \\
aktivitas perdagangan (Vardrajan dan Yadav, \\
2002). Perubahan tersebut salah satunya terlihat \\
dari proses pembelian. Proses pembelian \\
sebelum adanya internet individu harus pergi \\
ke tempat barang yang diinginkan, akan tetapi \\
dengan perkembangan internet individu dapat \\
melakukan pembelian di rumah melalui katalog \\
belanja tradisional, tele-shoping, dan yang \\
sedang populer saat ini yaitu pembelian secara \\
online (Sarma dan Sarma, 2011). \\
Selain membawa perubahan pada perilaku \\
manusia, perkembangan internet juga akan ber-
\end{tabular}

dampak pada ketersediaan informasi. Ketersediaan informasi akan lebih banyak jumlahnya sehingga akan memungkinkan konsumen untuk menggumpulkan informasi alternatif (meliputi informasi tentang harga, fitur produk, dan detail produk) yang lebih banyak pula. Oleh karena itu, keadaan ini akan memaksa penjual untuk mengetahui perilaku konsumen dalam melakukan pencarian informasi (Vardrajan dan Yadav, 2002).

Beberapa penelitian sudah menguji faktor-faktor yang mendorong individu untuk melakukan pembelian secara online antara lain yaitu Feng et al. (2014); Wu et al. (2014); Allagui dan Lemoine, (2008). Namun, penelitian terdahulu kebanyakan berfokus pada atmosphere, desain website, maupun kualitas website. Penelitian yang menguji faktor yang mendorong 
individu untuk melakukan pembelian secara online dari sisi metode adaptasi presentasi masih jarang. Oleh karena itu, peneliti tertarik untuk menguji faktor yang mendorong individu untuk melakukan pembelian secara online dari sisi metode adaptasi khususnya tree-view.

Adaptasi presentasi tree-view didefinisikan oleh Adipat et al. (2011) sebagai pendekatan yang menyajikan isi dari halaman web dalam bentuk tree (pohon), hierarki bertingkat yang seolah-olah menampilkan konten web yang asli. Kelebihan yang dimiliki oleh adaptasi presentasi tree-view yaitu adaptasi tersebut sangat intuitif dan sudah sering digunakan pengguna, misal ketika melakukan browsing buku dengan melihat daftar isi (Ren et al., 2010; Tegarder, 1999).

Dari uraian sebelumnya penelitian ini mempunyai tiga pertanyaan penting yaitu (1) apakah metode adaptasi presentasi tree-view berdampak pada emosi dan sikap pengguna terhadap website?,(2) apakah emosi pengguna berdampak pada sikap pengguna terhadap website?, dan (3) apakah emosi dan sikap pengguna terhadap website akan mendorong individu untuk melakukan pembelian secara online?

\section{REVIEW LITERATUR DAN HIPOTESIS}

\section{Stimulus-Organism-Response}

Paradigma S-O-R (Stimulus-OrganismResponse) telah banyak digunakan dalam penelitian yang mengukur atau menguji pengaruh persepsi penguna tentang toko online terhadap tanggapan pengguna pada toko online. Paradigma S-O-R menyatakan bahwa rangsangan lingkungan akan mempengaruhi keadaan internal yang akhirnya akan berdampak pada tanggapan konsumen secara keseluruhan. Keadaan internal yang akan memediasi hubungan antara stimulus dengan tanggapan (response) individu (Manganari et al., 2011; Jeong et al., 2009)

\section{Stimulus: Adaptasi Presentasi tree-view}

Erouglu et al. (2003, 2001) menyatakan bahwa dalam kerangka kerja Stimulus-OrganismResponse (S-O-R), stimulus didefinisikan sebagai karakteristik dari dampak yang mempengaruhi internal states dari respons individu. Beberapa penelitian sudah menggunakan atmosphere, layout design, kualitas produk, kualitas layanan maupun web interface (Wu et al., 2014; Kim dan Lennon, 2013; Jang dan Namkung, 2009; Allogui dan Lemoine, 2008) sebagai stimulus dalam memprediksi niat untuk melakukan pembelian secara online.

Adaptasi presentasi tree-view didefinisikan oleh Adipat et al. (2011) sebagai pendekatan yang menyajikan isi dari halaman web dalam bentuk tree (pohon), hierarki bertingkat yang seolah-olah menampilkan konten web yang asli. Misal suatu website pertama kali akan menampilakan judul utama pada halaman web tersebut kemudian apabila pengguna mengklik judul utama tersebut maka tree akan memperluas dan menunjukan cabang-cabang berikutnya atau tree tersebut akan menampilkan secara lebih rinci sub dari judul utama tersebut. Adaptasi presentasi mempunyai manfaat bagi pengguna yaitu pengguna akan lebih mudah dalam menemukan informasi yang dicari, waktu yang dibutuhkan untuk menemukan informasi lebih cepat (Adipat et al., 2011)

Salah satu kesulitan yang dialami pengguna ketika melakukan aktivitas browsing yaitu pengguna sulit dalam menemukan informasi yang tepat. Penyebab kesulitan tersebut antara lain seperti yang diungkapkan oleh Olshton dan Chi (2003); Pirolli (2007) yaitu kurangnya informasi yang disediakan oleh suatu website.

\section{Organism: Emosi dan Sikap Pengguna Terhadap Website}

Erouglu (2001, 2003) menyatakan bahwa internal state diwakili oleh proses yang memediasi antara stimulus dan respon individu. 
Organism direpresentasikan oleh sikap afektif dan kognitif (Kim dan Lennon, 2013). Organism yang digunakan dalam penelitian ini yaitu emosi dan sikap pengguna terhadap website.

Respon emosional dalam penelitian ini diukur dengan pandangan unipolar. Penggunaan pandangan unipolar dengan alasan bahwa pandangan bipolar (teori pleasure-arousaldominace) yang sering digunakan dalam penelitian psikologi telah dikritik (Kritik dikemukakan oleh Babin et al. (1998)) dalam Westbrook (1997)

Kritik tersebut meliputi pandangan bipolar hanya meliputi perasaan yang berlawanan (misal menyenangkan/ tidak menyenangkan), serta tidak memadai untuk menerangkan emosi konsumen (misal emosi negatif tidak menutup kemungkinan timbulnya emosi positif). Organism lain yang digunakan dalam penelitian ini yaitu sikap pengguna terhadap website.

\section{Response: Niat untuk Melakukan Pembelian Secara Online}

Response dalam kerangka S-O-R merupakan sebuah konsekuensi akhir seperti kepuasaan pelanggan, perilaku pendekatan (perilaku penggunaan) maupun perilaku penghindaran terhadap sesuatu (Erouglu et al., 2003, 2001).

Niat pembelian merupakan salah satu cara untuk memprediksi perilaku konsumen, dan niat pembelian merupakan satu dimensi dengan niat perilaku (Zaithaml et al., 1996). Boulding et al. (1993) mengungkapkan bahwa dimensi perilaku yang sering digunakan sebagai variabel response dalam penelitian antara lain yaitu niat pembelian/niat pembelian kembali, perilaku pembelian aktual/perilaku pembelian aktual kembali, toleransi harga, dan kecenderungan untuk melakukan pembelian tambahan dengan sumber yang sama. Oleh karena itu, penggunaan dimensi perilaku tersebut sebagai variabel hasil (respons) penting ketika pengguna melakukan kunjungan awal dalam sebuah website.
Dari uraian sebelumnya maka model penelitian yang ditawarkan adalah sebagai berikut.

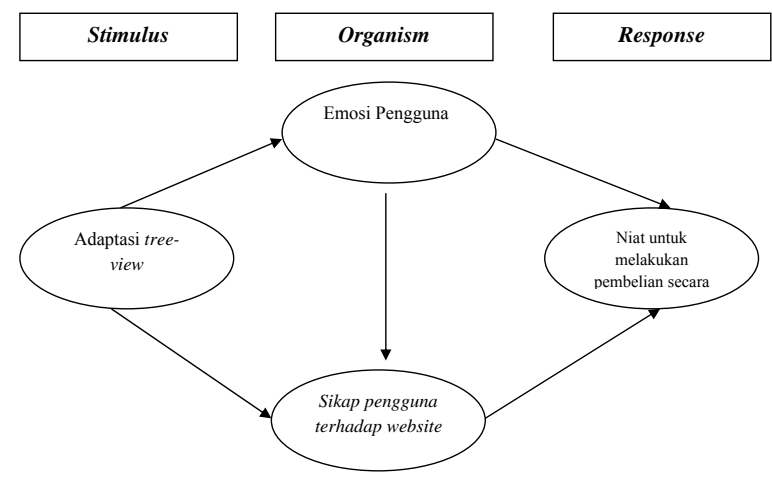

\section{Gambar 1 \\ Model Konseptual Penelitian}

\section{Pengembangan Hipotesis}

Hubungan Antara Adaptasi Presentasi TreeView dengan Emosi Pengguna

Gautis dan Gaiciukynaite (2013) mengungkapkan bahwa adaptasi presentasi merupakan salah satu bagian dari kategori virtual layout and design. Ketika suatu website menggunakan adaptasi presentasi tree-view maka pengguna akan lebih mudah dalam menemukan informasi yang dicari (Adipat et al., 2011).

Sehingga dengan manfaat yang diberikan ketika suatu website menggunakan adaptasi treeview, pengguna akan mencapai pengalaman yang optimal saat melakukan aktivitas browsing, dan sebaliknya ketika metode adaptasi tersebut tidak akrab dengan pengguna, pengguna mempunyai kecenderungan untuk tersesat dalam dunia maya, dan sebagai konsekuensinya pengguna tersebut akan mengalami kecemasan ketika berada dalam suatu website (Allagui dan Lemoine, 2008).

Oleh karena itu, penggunaan adaptasi presentasi tree-view akan meningkatkan emosi pengguna. Peningkatan emosi disebabkan karena dengan penggunaan adaptasi tree-view pengguna akan lebih mudah dalam menemukan informasi yang dicarinya dan pengguna sudah akrab (user 
friendly) dengan metode tersebut. Sehingga hipotesis pertama penelitian ini yaitu sebagai berikut.

$\mathrm{H}_{1}$ : Adaptasi presentasi tree-view akan meningkatkan emosi pengguna online saat melakukan pencarian informasi pada suatu website.

Hubungan Antara Adaptasi Presentasi TreeView dengan Sikap Pengguna Terhadap Website

Alur persuasi yang ada pada model elaborasi kemungkinan (elaboration likelihood model/ELM) yaitu sentral dan perifel. Alur sentral membutuhkan upaya yang signifikan untuk meneliti informasi-informasi yang signifikan, sedangkan alur perifel akan dipengaruhi oleh faktor-faktor konstektual, yang akhirnya kedua alur tersebut akan menentukan perubahan sikap (Petty dan Caciopo, 1986).

Isyarat perifel dalam konteks elaboration likelihood model/ELM online digunakan oleh pemasar untuk membujuk konsumen yang akhirnya akan mendorong konsumen untuk mengevaluasi sebuah toko berdasarkan unsurunsur virtual layout and atmosphere (Fink et al., 2008; Vrechoupulus et al., 2004; Erouglu et al., 2001). Lebih lanjut, Hong et al. (2004); Allaguine dan Lemoine (2008) mengungkapkan bahwa web interface design memainkan peran penting dalam mempengaruh sikap konsumen terhadap website. Oleh karena itu, website design yang lebih kondusif untuk tugas-tugas pengguna akan meningkatkan sikap yang lebih positif dikalangan pengguna dan meningkatkan ketersediaan pengguna untuk mengunjungi kembali website tersebut (Allagui dan Lemoine, 2008).

Metode adaptasi presentasi tree-view merupakan metode presentasi yang secara kondusif dapat membantu pengguna website untuk menemukan target informasi secara akurat dan metode adaptasi presentasi treeview juga dipersepsikan oleh pengguna mudah dalam menggunakanya (Adipat et al., 2011). Oleh karena itu, dari manfaat tersebut maka suatu website yang menggunakan adaptasi treeview akan menimbulkan sikap positif pengguna terhadap website. Sehingga hipotesis kedua penelitian ini yaitu sebagai berikut.

$\mathrm{H}_{2}$ : Adaptasi presentasi tree-view berdampak positif pada sikap pengguna terhadap website.

\section{Hubungan Emosi dengan Sikap Pengguna Terhadap Website}

Faktor yang dapat mempengaruhi kepuasaan pelanggan dan perilaku penerimaan secara keseluruhan antara lain yaitu dari tingkat kesenangan yang dialami pengguna selama melakukan belanja online (Erouglu et al., 2003, 2001). Hal serupa juga diungkapkan oleh Mummalaeni (2005) yang mengungkapkan bahwa kesenangan akan mempengaruhi kepuasaan konsumen, niat loyalitas, dan jumlah barang yang dibeli. Oleh karena itu, hipotesis ketiga penelitian ini yaitu sebagai berikut.

$\mathrm{H}_{3}$ : Emosi pengguna berdampak positif pada sikap pengguna terhadap website.

\section{Hubungan Emosi Pengguna dengan Niat} Untuk Melakukan Pembelian Secara Online

Emosi konsumen merupakan faktor utama yang mendorong perilaku pembelian, evaluasi, dan proses pengambilan keputusan (Ladhari et al., 2008). Hal serupa diungkapkan oleh Baker et al. (1992) yang menyatakan bahwa keadaan emosional berhubungan positif dengan kemauan untuk membeli. Pengguna dalam keadaan emosi positif cenderung membuat otak lebih efisien, lebih fleksibel, dan lebih inovatif (Isen, 2001), dengan demikian ketika pembeli mengalami emosi positif didaerah pembelajaan pembeli cenderung mengadopsi perilaku pendekatan/ niat pembelian (Kim dan Lennon, 2013; Jang dan Namkung, 2009; Yalch dan Spangenberg, 2000). Oleh karena itu, hipotesis keempat penelitian ini yaitu sebagai berikut. 
$\mathrm{H}_{4}$ : Emosi pengguna berdampak positif terhadap niat untuk melakukan pembelian secara online.

\section{Hubungan Sikap Pengguna Terhadap Website dengan Niat untuk melakukan Pembelian secara Online}

Theory of reaction action (TRA) menyatakan sikap individu dan norma subyektif merupakan penentu perilaku individu (Fishbein dan Ajzen, 1995). Hal ini didukung oleh penelitian yang menerapkan technology acceptance model seperti Vijayasarnthy dan Jones (2004) yang menemukan bahwa sikap positif pengguna terhadap website secara positif dan signifikan berkorelasi positif dengan niat untuk melakukan pembelian dari website. Oleh karena itu, hipotesis kelima penelitian ini yaitu sebagai berikut.

$\mathrm{H}_{5}$ : Sikap pengguna terhadap website berdampak positif pada niat untuk melakukan pembelian secara online.

\section{METODE PENELITIAN}

\section{Prosedur}

Pengumpulan data dalam penelitian ini dilakukan dengan metode survey, baik yang didistribusikan secara langsung maupun melalui online (melalui email dan jejaring sosial). Populasi penelitian ini yaitu pengguna yang melakukan aktivitas dengan internet, sedangkan pengambilan sampel dilakukan dengan teknik purposive sampling. Kriteria sampel yang digunakan dalam penelitian ini yaitu pengguna yang pernah melakukan browsing pada toko online dan minimal telah melakukan dua kali pembelian secara online.

\section{Instrumen}

Skala yang digunakan dalam penelitian diadaptasi dan dikembangkan dari penelitian terdahulu, dan skala yang digunakan dalam penelitian ini yaitu skala likert 7 (sangatsangat tidak setuju (1) sampai dengan sangatsangat setuju (7). Berikut merupakan ringkasan dari definisi operasional, dan skala penelitian terdahulu yang digunakan.

Tabel 1

Ringkasan Definisi Operasional, dan Skala Penelitian Terdahulu

\begin{tabular}{|c|c|c|c|}
\hline Keterangan & $\begin{array}{l}\text { Sumber } \\
\text { Definisi }\end{array}$ & Definisi & $\begin{array}{l}\text { Referensi } \\
\text { Sumber } \\
\text { Skala yang } \\
\text { digunakan }\end{array}$ \\
\hline $\begin{array}{l}\text { Adaptasi presentasi } \\
\text { tree-view }\end{array}$ & $\begin{array}{l}\text { Adipat et al. } \\
\text { (2011) }\end{array}$ & $\begin{array}{l}\text { Pendekatan yang menyajikan } \\
\text { isi dari suatu halaman website } \\
\text { dengan tipe pohon, hierarki } \\
\text { bertingkat yang seolah-olah } \\
\text { ingin menampilkan konten } \\
\text { web asli. }\end{array}$ & $\begin{array}{l}\text { Allagui dan } \\
\text { Lemoine } \\
\text { (2008). }\end{array}$ \\
\hline Emosi & $\begin{array}{l}\text { Winkielman et } \\
\text { al. (2007) }\end{array}$ & $\begin{array}{l}\text { Kondisi kesiapan mental } \\
\text { yang muncul dari penilaian } \\
\text { kognitif suatu peristiwa } \\
\text { atau pikiran yang memiliki } \\
\text { nada fenomologis dan } \\
\text { disertai dengan peristiwa } \\
\text { fisiologis, dan akhirnya emosi } \\
\text { sering dinyatakan dengan } \\
\text { peristiwa fisik yang dapat } \\
\text { mengakibatkan tindakan } \\
\text { khusus. }\end{array}$ & $\begin{array}{l}\text { Jang dan } \\
\text { Namkung } \\
\text { (2009) }\end{array}$ \\
\hline $\begin{array}{l}\text { Sikap terhadap } \\
\text { website }\end{array}$ & Wu et al. (2014) & $\begin{array}{l}\text { Evaluasi emosional yang } \\
\text { dilakukan individu setelah } \\
\text { melakukan aktivitas browsing } \\
\text { pada suatu website }\end{array}$ & $\begin{array}{l}\text { Wu et al. } \\
\text { (2014) }\end{array}$ \\
\hline $\begin{array}{l}\text { Niat untuk } \\
\text { melakukan } \\
\text { pembelian secara } \\
\text { online }\end{array}$ & Wu et al. (2014) & $\begin{array}{l}\text { Kekuatan niat konsumen } \\
\text { untuk melakukan pembelian } \\
\text { melalui internet. }\end{array}$ & $\begin{array}{l}\text { Wu et al. } \\
\text { (2014) }\end{array}$ \\
\hline
\end{tabular}

HASIL PENELITIAN DAN PEMBAHASAN

\section{Sampel}

Kuisioner yang digunakan dalam penelitian ini berjumlah 220 responden. Responden mayoritas berjenis kelamin perempuan. Jumlah responden perempuan dalam penelitian ini berjumlah 135 orang (61,36\%). Ditinjau dari segi usia menunjukan bahwa usia yang mendominasi dalam penelitian ini yaitu 21-25 tahun (55\%). Tingkat responden yang mendominasi dalam penelitian ini yaitu sarjana (S-I) sebanyak 166 orang $(75,45 \%)$, sedangkan profesi yang mendominasi yaitu mahasiswa sebanyak 180 orang $(81,82 \%)$. Berikut data demografi responden dalam penelitian ini (Tabel. 2). 
Tabel 2

Demografi Responden

\begin{tabular}{|c|c|c|c|}
\hline Keterangan & Pengukur & Jumlah & Persentase \\
\hline Jenis & Laki-Laki & 85 & $38,64 \%$ \\
Kelamin & Perempuan & 135 & $61,36 \%$ \\
\cline { 2 - 4 } & Total & $\mathbf{2 2 0}$ & $\mathbf{1 0 0 \%}$ \\
\hline \multirow{6}{*}{ Usia } & $15-20$ & 121 & $37,73 \%$ \\
& $21-25$ & 11 & $55 \%$ \\
& $26-30$ & 4 & $5 \%$ \\
& $31-35$ & 1 & $1,81 \%$ \\
& $>36$ & $\mathbf{2 2 0}$ & $0,46 \%$ \\
\cline { 2 - 4 } Tingkat & Jumlah & $\mathbf{1 0 0 \%}$ \\
\hline \multirow{4}{*}{ Pendidikan } & SMA/SMK & 6 & $0,91 \%$ \\
& Diploma & 20 & $2,73 \%$ \\
& Profesi & 166 & $9,09 \%$ \\
& S1 & 26 & $75,45 \%$ \\
& S2 & $\mathbf{2 2 0}$ & $11,82 \%$ \\
\cline { 2 - 4 } & Total & $\mathbf{1 0 0 \%}$ \\
\hline Pekerjaan & Mahasiswa & 180 & $81,82 \%$ \\
& Pelajar & 1 & $0,45 \%$ \\
& Bekerja & 39 & $17,73 \%$ \\
\cline { 2 - 4 } & Total & $\mathbf{2 2 0}$ & $\mathbf{1 0 0 \%}$ \\
\hline
\end{tabular}

Sumber: Data primer, diolah (2014)

\section{Model Pengukuran (Outer Model)}

Sebelum melakukan pegujian hipotesis, penelitian ini melakukan pengujian model pengukuran terlebih dahulu yang bertujuan untuk memverifikasi indikator dan variabel laten yang dapat diuji selanjutnya. Pengujian tersebut meliputi pengujian validitas konstruk dan reliabilitas. Validitas konstruk terdiri dari validitas konvergen dan validitas diskriminan (Hartono, 2008).

Semua indikator adaptasi tree-view dan niat untuk melakukan pembelian secara online memiliki faktor loading lebih besar dari 0,7 dan memiliki nilai AVE masing-masing lebih besar dari 0,5. Oleh karena itu, semua indikator adaptasi tree-view, tree-view yang ditambah dengan ringkasan teks sekaligus kata kunci berwarna terang, dan niat untuk melakukan pembelian secara online valid.

Indikator emosi pengguna, dan sikap pengguna terhadap website tidak semua indikatornya memiliki faktor loading lebih besar dari 0,7. Indikator tersebut yaitu E4 $(0,693)$, S3 $(0,699)$, S4 $(0,665)$ dan S6 $(0,666)$ memiliki faktor loading kurang dari 0,7, namun Hartono dan Abdillah (2014) menyarankan bahwa indikator yang mempunyai skor loading 0,5-
0,6 agar tidak dihapus sepanjang nilai AVE > 0,5 . Oleh karena itu, peneliti tidak menghapus indikator yang mempunyai skor loading dibawah 0,7, hal ini karena semua konstruk yang memiliki skor loading dibawah 0,7 memiliki nilai AVE > 0,5 .

Dari uraian sebelumnya maka penelitian ini memenuhi uji validitas konvergen. Penelitian ini juga memenuhi uji validitas diskriminan, hal ini dapat dilihat dari skor loading diatas 0,7 maupun 0,5-0,6 sepanjang nilai AVE $>0,5$, serta skor loading indikator tersebut masih lebih tinggi dari skor loading indikator konstruk lain dan nilai masih mengumpul pada masing-masing konstruk tersebut. Validitas diskriminan juga dapat dilihat dari nilai akar AVE yang lebih tinggi dari korelasi antar variabel. Hasil uji validitas ditunjukan pada tabel 3 dan 4 . Tabel 3 dan 4 menunjukan bahwa penelitian ini memenuhi uji validitas diskriminan.

Tabel 3

Hasil Uji Validitas Konvergen

\begin{tabular}{|l|l|l|}
\hline \multicolumn{1}{|c|}{ Indikator } & Faktor loading & $\begin{array}{c}\text { Average } \\
\text { Variance } \\
\text { Extracted (AVE) }\end{array}$ \\
\hline Tree-View & 0,763 & \\
TV1 & 0,704 & 0,557 \\
TV2 & 0,779 & \\
TV3 & 0,736 & \\
TV4 & & \\
\hline EMOSI & 0,702 & \\
Positif & 0,762 & 0,591 \\
E1 & 0,707 & \\
E2 & 0,693 & \\
E3 & 0,795 & \\
E4 & 0,824 & \\
Negatif & 0,851 & \\
E5 & 0,798 & \\
E6 & & \\
E7 & 0,734 & \\
E8 & 0,764 & \\
Sikap pengguna terhadap & & \\
website & 0,699 & \\
S1 & 0,665 & \\
S3 & 0,767 & \\
S4 & 0,666 & \\
S5 & & \\
S6 Niat untuk melakukan & 0,851 & \\
pembelian secara online & 0,862 & \\
P1 & 0,862 & \\
P2 & & \\
P3 & & \\
Sumber: Data primer, dis & $0 l a h(2014)$ \\
\hline
\end{tabular}

Sumber: Data primer, diolah (2014) 
Tabel 4

Hasil Uji Validitas Diskriminan

\begin{tabular}{|l|r|r|r|r|}
\hline & \multicolumn{1}{|c|}{ TV } & \multicolumn{1}{c|}{ E } & \multicolumn{1}{c|}{ S } & P \\
\hline TV & $\mathbf{( 0 . 7 4 6 )}$ & & & \\
\hline E & 0.646 & $\mathbf{( 0 . 7 7 0 )}$ & & \\
\hline S & 0.474 & 0.600 & $\mathbf{( 0 . 7 1 7 )}$ & \\
\hline P & 0.378 & 0.490 & 0.668 & $\mathbf{( 0 . 8 5 8 )}$ \\
\hline
\end{tabular}

Sumber: Data primer, diolah (2014)

Penelitian ini juga memenuhi uji reliabilitas. Hal ini dapat ditunjukan dengan nilai croanbach's alpha dan composite reliability lebih besar dari 0,7. Hasil uji reliabilitas ditunjukan pada tabel 5 .

\section{Tabel 5}

Hasil Uji Reliabilitas

\begin{tabular}{|c|c|c|}
\hline Konstruk & $\begin{array}{c}\text { Cronbach's } \\
\text { alpha }\end{array}$ & $\begin{array}{c}\text { Composite } \\
\text { reliability }\end{array}$ \\
\hline TV & 0,734 & 0,834 \\
\hline E & 0,900 & 0,920 \\
\hline S & 0,810 & 0,863 \\
\hline P & 0,821 & 0,893 \\
\hline
\end{tabular}

Sumber: Data primer, diolah (2014)

Dari uraian sebelumnya maka penelitian ini memenuhi pengujian model pengukuran (outer model). Oleh karena itu, tahap selanjutnya penelitian ini melakukan penggujian model stuktural (inner model). Pengujian model struktural (inner model) dilakukan dengan menggunakan $R$-Square atau nilai $t$-value tiap path. Hasil model struktural disajikan pada gambar 2 .

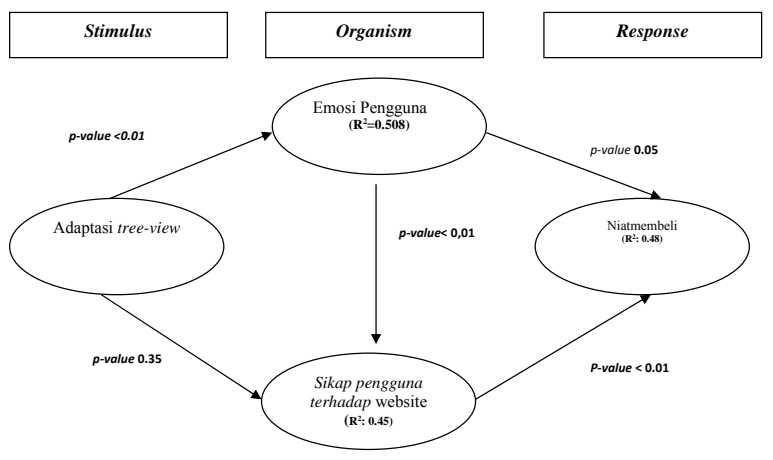

Sumber: Data primer, diolah (2014)

Gambar 1

Model Struktural
Emosi pengguna memiliki nilai $R$-Square 0,508 . Hal ini berati bahwa variasi perubahan variabel emosi yang dijelaskan oleh variabel adaptasi tree-view adalah 50,8\% sedangkan sisanya dijelaskan oleh variabel lain diluar model penelitian ini. Sikap pengguna terhadap website memiliki nilai $R$-Square 0,452. Hal ini berati bahwa variasi perubahan variabel sikap pengguna terhadap website yang dijelaskan oleh variabel adaptasi tree-view dan emosi adalah 45,2\% sedangkan sisanya dijelaskan oleh variabel lain diluar model penelitian ini.Niat untuk melakukan pembelian secara online memiliki nilai $R$-Square 0,480 . Hal ini berati bahwa variasi perubahan variabel niat untuk melakukan pembelian online yang dijelaskan oleh variabel emosi pengguna dan sikap pengguna terhadap website adalah $48 \%$ sedangkan sisanya dijelaskan oleh variabel lain diluar model penelitian ini.

Emosi pengguna saat melakukan aktivitas browsing dapat meningkat ketika suatu website menggunakan metode adaptasi tree-view. Hal ini berarti bahwa H1 ( $p$-value $<0,01)$ terdukung, akan tetapi ketika suatu website menggunakan adaptasi tree-view tidak mempunyai dampak terhadap sikap pengguna terhadap website. Hal ini berarti $\mathrm{H} 2$ ( $p$-value 0, 35).

Emosi pengguna saat melakukan aktivitas browsing dalam suatu website juga berdampak pada sikap pengguna terhadap website, atau dengan kata lain $\mathrm{H} 3$ ( $p$-value $<0,01)$ terdukung. Emosi dan sikap pengguna terhadap website akhirnya akan mendorong individu untuk melakukan pembelian secara online. Hal ini bearti bahwa H10 ( $\beta 0,10$, p-value 0,05$)$ dan H11 $(\beta 0,62$, $p$-value $<0,01)$ terdukung.

\section{KESIMPULAN DAN SARAN}

Metode adaptasi tree-view mempunyai dampak terhadap emosi pengguna, akan tetapi adaptasi tree-view tidak mempunyai dampak pada sikap pengguna terhadap website kemungkinan 
disebabkan karena adaptasi tree-view tidak sesuai dengan tugas atau rumit untuk digunakan). Emosi pengguna saat melakukan browsing pada suatu website akan mempunyai dampak pada sikap pengguna terhadap website tersebut. Akhirnya, emosi pengguna saat browsing pada suatu website dan sikap pengguna terhadap website, akhirnya akan mendorong individu untuk melakukan pembelian online.

Penelitian ini mempunyai beberapa keterbatasan antara lain yaitu (1) penelitian ini menggunakan metode survey, sehingga penelitian ini mempunyai keterbatasan seperti yang melekat pada metode survey yaitu memiliki validitas internal yang rendah. Sehingga, penelitian selanjutnya dapat menggunakan metode eksperimen. (2) penelitian ini menggunakan pandangan unipolar untuk mengukur respon emosional, sehingga penelitian ini tidak begitu pasti fitur adaptasi tree-view akan meningkatkan emosi positif atau menurunkan emosi negatif pengguna serta emosi mana (positif/negatif) yang akan mendorong individu untuk melakukan pembelian secara online. Oleh karena itu, penelitian selanjutnya dapat menggunakan pandangan bipolar. (3) penelitian ini hanya terbatas pada metode adaptasi presentasi treeview sebagai stimulus, sehingga kemungkinan ada variabel lain yang dapat menjadi stimulus antara lain yaitu link dan meniu. (4) sampel dalam penelitian ini yaitu individu yang sudah familiar dengan adaptasi presentasi tree-view. Oleh karena itu, penelitian selanjutnya dapat membedakan individu yang sudah familiar dengan adaptasi tree-view dengan individu yang belum familiar dengan adaptasi tree-view.

\section{DAFTAR PUSTAKA}

Adipat, Boonlit., D. Zhang, dan L. Zhou. 2011. The Effect of Tree View Based Presentation Adaptation On Mobile Web Browsing. MIS Quarterly 35, no. 1: 99121.
Allagui, Anis, dan J-F. F. Lemoine. 2008. Web Interface and Consumers' Buying Intention in e-Tailing: Result From an Online Experiment. European Advances in Consumer Research 8, 24-30.

Babin, B. J., W. R. Darden, dan L. A. 1998. Negative Emotion in Marketing Research: Affect or Artifact?. Journal of Business Research, no. 42: 271-285.

Baker, J., D. Grewal, dan M. Levy. 1992. An Experimental Approach to Making Retail Store Environment Decisions. Journal of Retailing 68, 445-460.

Boulding, William., A. Kalra., R. Staelin, dan V. Zeiyhaml. 1993. A Dynamic Process Model of Service Quality: Fro, Expectations to Behavioral Intentions. Journal of Marketing Research 30, no. 1: 7-27.

Erouglu, Sevgin, A., K. A. Machleit, dan L. M. Davis. 2001. Atmopheric Qulities of Online Retailing: A Conceptual Model and Implications. Journal of Business Research 54, 177-184.

.2003. Empirical Testing of a Model of Online Store Atmospherics and Shopper Responses. Psychology and marketing 20, no 2. 139-150.

Feng, Te-Tai., Chengli., Zhi-Yuang, Feng, dan Pin-Jhen Lai. 2014. Web Site Quality and Online Trading Influences on Customer Acceptance of Securities Brokers. Asia Pacific Management Review 19, no. 1: 25-45.

Fink, L., A. Zeevi, dan D. Te'eni. 2008. The Effectiveness of Online Customer Relation Tools: Comparing the Perspectives of Organizations and Customer. Internet Research 18. No. 3: 211-228. 
Fishbein, M, dam I. Ajzen. 1975. Belief, Attitide, Intention, and Behavior: An Introduction to Theory and Research. AddisionWesley, Reading, MA.

Gatautis, Rimantas., E. Vaicukynaite. 2013. Website Atmosphere: Towards Revisited Taxonomy of Website Elements. Economics and Management 18, no. 3: 537-544.

Hartono, Jogiyanto . 2008. Metodologi Penelitian Sistem Informasi. Edisi 1. Yogyakarta, Indonesia: ANDI OFFSET.

, dan W. Abdillah. 2014. Konsep dan Aplikasi PLS (Partial Least Square) untuk Penelitian Empiris. Edisi 1. Yogyakarta, Indonesia: BFFE UGM.

Hong, W., J. Y. L. Thong, dan K. Y. Tam. 2004. The Effect of Information Format and Shopping Task on Consumer' Online Shopping Behavior: A Cognitive Perspective. Journal Management Information System.

Isen, A. M. 2001. An Influence of Positive Affect on Decision maiking In Complex Situations: Theoretical Issues With Practical Implications. Journal of Consumer Psychology 11, no. 2: 75-85.

Jang, SooCheong (Shawn), dan Y. Namkung. 2009. Perceived Quality, Emotions, and behavioral Intentions: Application of An Extended Mehrabian- Russell Model to Restaurants. Journal of Business Research 62, 451-460.

Jeong, S. W., A. M. Flore., L. S. Niehm, dan F. O. Lorenz. 2009. The Role Experiential Value in Online Shopping: The Impact of Product Presentation on Consumer Response Towards as Apparel website. Internet Research 19, no. 1: 105-124.

Kim, Jiyoung, dan S. J. Lennon. 2013. Effect of Reputation and Website Quality On Online Consumers' Emotion, Perceived Risk and Purchase Intention: Based On
Stimulus-Organism-Response Model. Journal of Research In Interactive Marketing 7, no. 1: 33-56.

Ladhari, R., I. Brun, dan M. Morales. 2008. Determinats of Dining Satisfaction and Post-Dining Behavioral Intentions. International Journal of Hospitality management 27, no. 4: 563-573.

Manganari, E.E., G. J. Siomkos., I. D. Rigopolou, dan A. P. Vrechopoulus. 2011. Virtual Store Layout Effect on Consumer Behavioral: Applying an Enviromental Psychology Approach in the Online Travel Industri. Internet Research 21, no. 3 : 326-346.

Mummalaneni, V. 2005. An Empirical Investigation of Web Characteristics, Consumer Emotion states, and Online Shopping Behaviours. Journal of Business Research 58, no. 4: 526-532.

Olston, Chris, dan E. D. Chi. 2003. ScentTrails Integrating Browsing and Searching on the web. ACM Transactions on Computer-Human Interaction 10, no. 3 : 177-197.

Petty, R. E., J. T. Cacioppo. 1986. The Elaboration Likelihood Model Of Persuasion. Advances In Experimental Social Psychology 19, 123-162.

Pirolli, Peter. 2007. Information Foraging Theory: Adaptive Interaction With Information. Nwe York: oxford University Press.

Ren, Kan., R. Sarvas, dan J. Calic. 2010. Interface Search and Browsing Interface for Large Scale Visual Repositories. Multimed Tools Appl 49, 513-528.

Sarmah, Upakul, dan M. K. Sarma. 2011. Service Quality Check: Online Shopping. SCMS Journal of Indian Management, 5-10.

Tegarder, David P. 1999. Business Information Visualization. Communication of the Association for Information Systems 1, no. $4: 1-38$ 
Varadarajan, P. Rajan, dan M. S. Yadav. 2002. Marketing Startegy and the Internet: An Organizing Framework. Journal of Academy Marketing Science 30,no. 1: 296-312.

Vijayasarathy, L. R, dan J. M. Jones. 2004. Intentions to Shop Using Internet Catalogues: Exploring the Effect of Product Types, Shoping Orientation, and Attitude Towards Computer. Electronic Markets 10, no.1: 29-38.

Vrechopoulus, A. P., R. M. O'Keefe., G. I. Doukidis, dan G. J. Siomkos. 2004. Virtual Store Layout: An Experimental Comparison in the Context of Grocery Retail. Journal of Retailing 80, no. 1: 13-22.

Westbrook, R.A. 1987. Product/ConsumptionBased a Affective and Post Purchase Processes. Journal of Marketing Research, no. 24: 258-270.
Winkielman, Piotr., B. Knutson., M. Paulus, dan J. L. Trujillo. 2007. Affective Influence on Judgments and Decision: Moving Towards Core Mchanisms. Review of General Psychology 11, no. 2: 179-192.

Wu, Wan-Yih., Chia-Ling Lee., Chen-su Fu., Hong-Chun Wang. 2014. How Can Online Store Layout Design and Atmosphere Influence Consumer Shopping Intention on a Website? International Journal of Retail and Distribution Management 42, no. 1: 4-24.

Yalch, R. F, dan E. R. Spangenberg. 2000. The Effect of Music in a Retail Setting on Real and Perceived Shopping times. Journal of Business Research 49, 139147

Zaithaml, Valarie A., L. L. Berry, dan A. Parasuraman. 1996. The Behavioral Consequences of Service Quality. Journal of Marketing 60, 31-46. 